\title{
Clinical and radiologic characteristics of symptomatic pregnant women with COVID-19 pneumonia
}

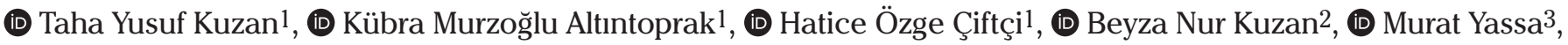 \\ (D) Niyazi Tuğ ${ }^{3}$, (D) Nuri Çagatay Çimşit ${ }^{2}$ \\ ${ }^{1}$ Clinic of Radiology, Sancaktepe Şehit Prof. Dr. İlhan Varank Training and Research Hospital, İstanbul, Turkey \\ 2Department of Radiology, Marmara University Faculty of Medicine, İstanbul, Turkey \\ ${ }^{3}$ Clinic of Obstetrics and Gynecology, Sancaktepe Şehit Prof. Dr. İlhan Varank Training and Research Hospital, İstanbul, Turkey
}

\section{Abstract}

Objective: To describe the radiological features, diagnostic accuracy and features of imaging studies and their relation with clinical course of Coronavirus disease-2019 (COVID-19) pneumonia in pregnant women.

Material and Methods: The clinical, laboratory and radiological features of symptomatic pregnant women suspected of COVID-19 were retrospectively reviewed. Chest radiography (CXR) and chest computed tomography (CT) findings of COVID-19 in pregnant women were identified.

Results: Fifty-five of eighty-one pregnant women were included in the final analysis. The most common admission symptoms were dry cough (45.4\%), fever (29.1\%) and dyspnea (34.5\%). Radiological imaging studies were performed in 34 (61.8\%) patients. Fourteen (66.7\%) of the laboratory-confirmed COVID-19 patients had parenchymal abnormalities on CXR, and most common abnormalities were airspace opacities (61.9\%) and prominent bronchovascular shadows (28.6\%). Seventeen (85.0\%) of the patients had parenchymal abnormalities consistent with COVID-19 on their chest CT. Chest CT most commonly showed bilateral (88.2\%), multilobe (100\%) involvement; peripheral and central distribution (70.6\%); patchy-shape (94.1\%) and ground-glass opacity (94.1\%). The sensitivity of CXR and chest CT was calculated as $66.7 \%$ and $83.3 \%$, respectively. Preterm birth rate was $41.2 \%(n=7 / 17)$. Five $(9.1 \%)$ of the 55 pregnant women admitted to the intensive care unit, three of those developed acute respiratory distress syndrome and one died.

Conclusion: This study describes the main radiological features of symptomatic pregnant women infected with COVID-19. The refusal rate among pregnant women for the imaging modalities involving ionizing radiation was high but these had high sensitivity for COVID-19 diagnosis. The preterm birth and cesarean section rates were observed as remarkably increased. (J Turk Ger Gynecol Assoc 2021; 22: 196-205)

Keywords: COVID-19, pregnancy, computed tomography, chest radiography, radiology

Received: 19 November, 2020 Accepted: 29 January, 2021

\section{Introduction}

Pregnancy is known to cause significant anatomical and physiological changes in respiratory function and these changes can increase susceptibility to respiratory tract infections and can quickly lead to respiratory failure (1). In addition, the modulation of the immune system during pregnancy leaves pregnant women vulnerable to viral infections, which may lead to even more severe symptoms (2). Previous studies have also shown that severe acute respiratory syndrome (SARS) and middle east respiratory syndrome infections were associated with serious maternal disease, maternal deaths, and spontaneous abortions (3-5). Pregnant women are at increased risk for severe illness from Coronavirus disease-2019 (COVID-19) compared to non- 
pregnant people $(6,7)$. Additionally, there may be an increased risk of adverse pregnancy outcomes, such as preterm birth, among pregnant women with COVID-19 (8,9). Moreover, the high refusal rate of imaging modalities involving ionizing radiation during pregnancy and the risks to fetuses present as a limiting factor in the diagnosis and treatment of pregnant women, making the diagnostic process more difficult when compared to the non-pregnant population (10). Therefore, pregnant women constitute a vulnerable group that requires special attention in the diagnosis and treatment of COVID-19.

The most commonly used reference standard in the diagnosis of COVID-19 is the reverse transcription polymerase chain reaction (RT-PCR) test. However, due to the technical limitations of the test and its relatively high false negative rate, radiological imaging including chest $\mathrm{CT}$ and chest radiography (CXR) play an important role in the diagnosis and evaluation of pregnant women suspected with COVID-19 infection $(11,12)$. Chest CT has been reported to be more sensitive than other modalities in the diagnosis of COVID-19 pneumonia (13).

Robust data concerning radiological and clinical features of pregnant women with COVID-19 pneumonia is scarce in the literature. This study aimed to identify the demographic characteristics and evaluate the clinical, laboratory, and radiological findings of symptomatic pregnant women with COVID-19 pneumonia.

\section{Material and Methods}

\section{Patient population and study design}

This retrospective study was conducted at two tertiary health care centers dedicated to treating severe acute respiratory syndrome-coronavirus-2 (SARS-CoV-2) pandemic between March $15^{\text {th }}$ and September $1^{\text {th }}$, 2020. Symptomatic pregnant women suspected of COVID-19 infection were included in the study. Patients who were tested for SARS-CoV-2 infection for universal screening purposes were not included in the study (14). Patients who refused chest CT or CXR with negative PCR test result were excluded. Those patients were managed according to the national guidelines (15). Pregnant women with COVID-19 infection confirmed either by PCR-testing or imaging studies were included to the final analysis (Figure 1). The disease was classified as mild, moderate and severe according to its clinical severity (15).

The demographic characteristics, clinical signs and symptoms, and laboratory results of the patients were obtained from the patients' electronic health records. Clinical symptoms, including fever $\left(\geq 37.3{ }^{\circ} \mathrm{C}\right)$, cough, dyspnea, sore throat, and fatigue, were assessed in terms of COVID-19. RT-PCR tests were performed using combined swab samples taken from the oropharynx and the nasopharynx of the patients, were used to confirm SARS-CoV-2 infection. The radiological examinations (CT and/or CXR) of the pregnant women were re-evaluated,

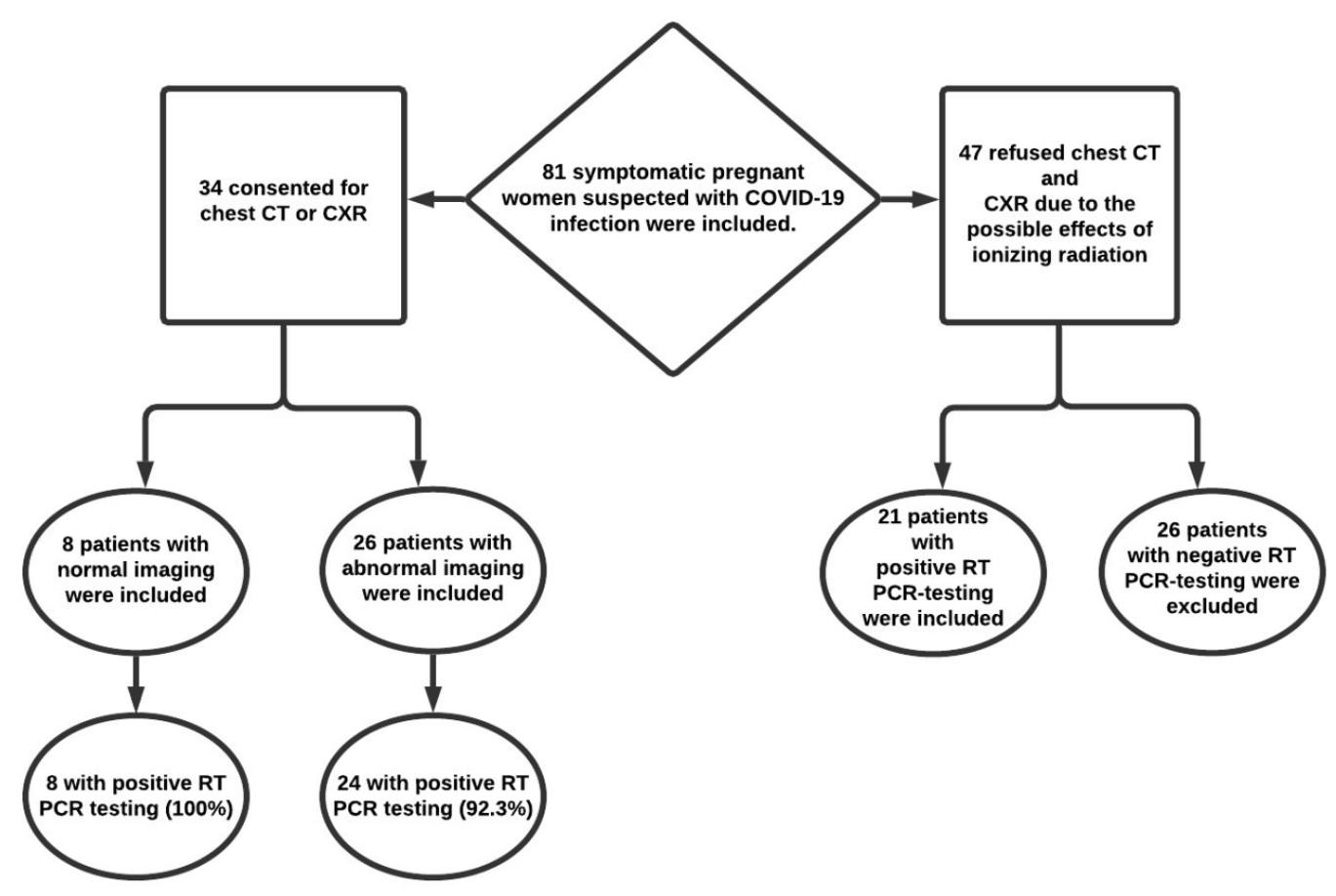

Figure 1. Flowchart of the study

CT: Computed tomography, CXR: Chest radiography, COVID-19: Coronavirus disease-2019, RT-PCR: Reverse transcription polymerase chain reaction 
independent from and blinded to the initial report. The study was approved by the Ethical Committee of the University of Health Sciences Turkey, Kartal Koşuyolu Training and Research Hospital (approval number: 2020.4/07-312) and the national health authorities.

\section{Radiological imaging}

Low-dose imaging protocol was followed. Radiological imaging criteria were met if at least two of the following symptoms were present: a fever above $38.3^{\circ} \mathrm{C}$, a respiratory rate of 22 breaths/minute and above, saturation of peripheral oxygen $\left(\mathrm{SpO}_{2}\right)$ below 93\%, or severe dyspnea. The possible effects of radiation exposure on the fetus were explained in detail and written consent was obtained from each patient. The choice of imaging method (CXR and/or CT) was decided together with the patient, considering diagnostic performance of imaging methods, the pregnancy trimester and the clinical condition of the patient.

CXR was performed using a digital X-ray machine (DRGEM Radiography System, South Korea). The CXR parameters were as follows: $75-110 \mathrm{kVp}, 4-8 \mathrm{mAs}$, and detector size $35 \times 43 \mathrm{~cm}$ with grid. During the examination, the abdomen and pelvis were protected with a lead sheath. The effective dose for CXR images did not exceed $0.07 \mathrm{mSv}$ (millisieverts).

Chest CT was performed in all patients using a 16 or 128-slice CT scanner (Optima 520 CT, GE company or Ingenuity Core 128, Philips Healthcare). CT images were obtained with the patient in the supine position at full inspiration and without contrast medium. For the pregnant participants, $80 \mathrm{kV}$ tube voltage, $50 \mathrm{mAs}$ automatic tube current modulation, $5 \mathrm{~mm}$ slice thickness, $5 \mathrm{~mm}$ slice interval, a noise index of 16, 36.0 DFOV, and 512 x 512 matrix were used. The thyroid, abdomen, and pelvis were protected by a lead sheath. The dose-length product was 25-100 mGy.

\section{Image analysis}

The reconstructed images were transmitted to the workstation and picture archiving and communication systems for multiplanar reconstruction post-processing. The chest radiographs and chest $\mathrm{CT}$ images of the cases were evaluated by three radiologists, blinded to RT-PCR results, at the radiology workstation. In cases where the three radiologists evaluated differently, the result was reached by consensus.

The CXR findings were classified as typical, indeterminate, atypical, and negative for COVID-19 (16). For statistical evaluation, typical and indeterminate groups were considered COVID-19 positive, and atypical and negative groups were accepted as COVID-19 negative. An example of chest CXR findings is shown in Figure 2.

CT findings were categorized as non-COVID-19, indeterminate COVID-19, probable COVID-19, and classic COVID-19 according to the COVID-19 infection version 2 of the British Society of Thoracic Imaging (17). For statistical evaluation, non-COVID-19 cases were categorized as CT negative group, while indeterminate COVID-19, probable COVID-19 and classic COVID-19 cases were categorized as CT positive group.

The distribution in the lung, shape, location, appearance, and size of the largest lesion were recorded. In addition, vascular enlargement, intralobular/interlobular septal thickening, air bronchogram, subpleural curvilinear lines, parenchyma findings such as bronchial wall thickening, fibrous bands, halo sign, and reversed halo sign were noted. Extrapulmonary findings such as pleural effusion, pleural thickening, and enlarged lymph nodes were also included. In the chest CT positive cases, CT severity index according to the degree of lesion distribution was calculated, as described previously (18).

\section{Statistical analysis}

Descriptive analyses were performed for the characteristics of the patients. The normally distributed continuous random variables were expressed as the mean \pm standard deviation

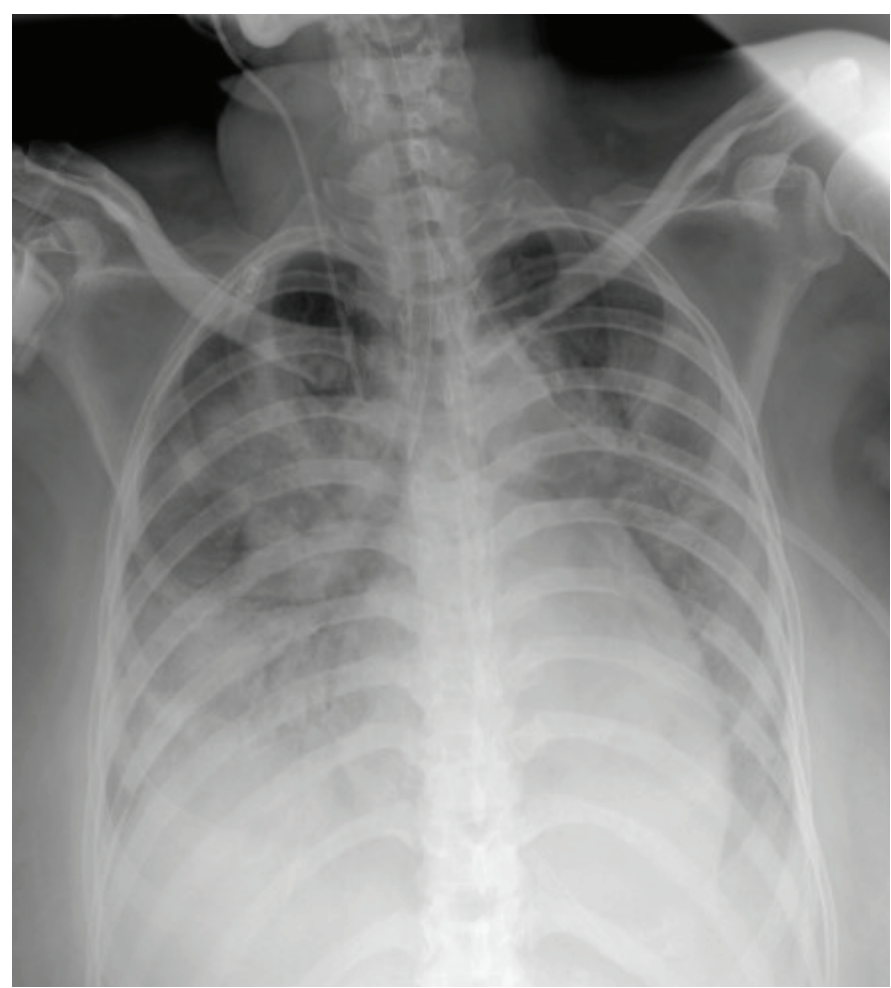

Figure 2. A 35-year-old, laboratory-confirmed COVID-19, pregnant woman with 25 weeks of pregnancy presented with fever and dyspnea. The patient developed hypoxic respiratory failure and was admitted to intensive care unit. Anteroposterior chest radiograph shows an ARDS pattern with ill-defined alveolar consolidation bilaterally in the predominantly lower zones

COVID-19: Coronavirus disease-2019, ARDS: Acute respiratory distress syndrome 
and categorical variables are expressed as percentages. Fisher's exact test was used to compare the severity of the disease between trimesters and the One-Way ANOVA test was used to compare the severity of pneumonia involvement (CT severity index). The sensitivity of CXR and chest CT was calculated for the diagnosis of COVID-19 disease, using RT-PCR as reference. SPSS 17.0 (IBM Inc., Armonk, NY, USA) was used for the statistical analyses.

\section{Results}

Eighty-one pregnant women suspected with COVID-19 infection were enrolled. Forty-seven patients (58.0\%) refused chest CT and CXR due to the risks of receiving ionizing radiation when pregnant. Out of these, 26 patients who had negative RTPCR-testing were excluded. Fifty-five pregnant women with COVID-19 infection confirmed either with RT-PCR-testing or imaging studies were included in the final analysis. Pregnant women were confirmed as having COVID-19 by RT-PCR alone $(n=29)$, imaging studies alone $(n=2)$, and both $(n=24)$. Radiological imaging studies were performed in 34 (61.8\%) patients. The positivity rate in PCR-testing among patients with abnormal imaging was $92.3 \%(n=24 / 26)$.

Demographic, clinical and laboratory characteristics of pregnant women are given in Table 1. The first, second, and third trimester distribution of pregnant women at the time of presentation were $n=8(14.6 \%), n=24$ (43.6\%), and $n=23$ (41.8\%), respectively. The patients' clinical condition was mild in eight (100\%) pregnant women in the first trimester. In the second trimester, 20 (83.3\%) cases were mild, 3 (12.5\%) cases were moderate, and 1 (4.2\%) case was severe, in the third trimester $18(78.3 \%)$ cases were mild, 2 (8.7\%) cases were moderate, and $3(13.0 \%)$ cases were severe. Although mild and severe cases were more frequent in the third trimester, the difference between trimesters was not statistically significant $(\mathrm{p}=0.672)$. CT severity index of pregnant women in first, second, and third trimesters was 3.7, 7.5, and 6.3, respectively. Although pneumonia involvement (CT severity index) was higher in the second and third trimester, the difference between trimesters did not reach a statistically significant level $(\mathrm{p}=0.697)$. During the study period, 12 cases gave birth by cesarean $(\mathrm{C} / \mathrm{S})$, and five cases had a normal spontaneous vaginal delivery, for a total of 17 cases delivered (seven preterm, 10 term), and one case of missed abortus at seven weeks. The remaining 37 were still pregnant during the study.

Five of 55 patients (9.1\%) were admitted to the intensive care unit (ICU). One patient and the fetus died in her $22^{\text {nd }}$ weeks of gestation due to acute respiratory distress syndrome (ARDS). CXR detail of that patient was common airspace opacities more prominent in the lower lobes, compatible with ARDS (Figure 2).
Repeated RT-PCR testing was performed in nine of 34 (26.5\%) patients whose first RT-PCR test was negative. Second RT-PCR test increased the COVID-19 positivity rate from 58.0\% (47/81) to $65.4 \%$ (53/81). There was no vertical transmission.

The radiological classification of imaging studies is summarized in Table 2. Twenty-one (61.8\%) of 34 patients underwent CXR and 20 of them underwent low-dose chest CT. In seven patients,

Table 1. Demographic, clinical and laboratory characteristics of pregnant women at presentation $(\mathbf{n}=55)$

\begin{tabular}{|c|c|c|}
\hline \multicolumn{3}{|l|}{ Patient demographics } \\
\hline \multicolumn{2}{|l|}{ Age mean \pm SD (range) } & $29.7 \pm 6.4(19-53)$ \\
\hline \multicolumn{2}{|l|}{ RT-PCR positivity n (\%) } & $53 / 81(65.4 \%)$ \\
\hline \multicolumn{3}{|l|}{ Presenting findings $\mathbf{n}(\%)$} \\
\hline \multicolumn{2}{|l|}{ Fever $\left(>37.3^{\circ} \mathrm{C}\right)$} & $16(29.1 \%)$ \\
\hline \multicolumn{2}{|l|}{ Dry cough } & $25(45.4 \%)$ \\
\hline \multicolumn{2}{|l|}{ Dyspnea } & $19(34.5 \%)$ \\
\hline \multicolumn{2}{|l|}{ Fatigue } & $11(20.0 \%)$ \\
\hline \multicolumn{2}{|l|}{ Sore throat } & $17(30.9 \%)$ \\
\hline \multicolumn{2}{|l|}{ Anosmia } & $5(9.1 \%)$ \\
\hline \multicolumn{2}{|l|}{ Suspicious contact } & $26(47.3 \%)$ \\
\hline \multicolumn{3}{|l|}{ Laboratory tests } \\
\hline \multirow{3}{*}{ WBC } & Low & $1(1.8 \%)$ \\
\hline & Normal & $43(78.2 \%)$ \\
\hline & High & $11(20.0 \%)$ \\
\hline \multirow{3}{*}{ Lymphocyte } & Low & $23(41.8 \%)$ \\
\hline & Normal & $32(58.2 \%)$ \\
\hline & High & $0(0 \%)$ \\
\hline \multirow{2}{*}{$\operatorname{CRP}(n=52)$} & Normal & $18(34.6 \%)$ \\
\hline & High & $34(65.4 \%)$ \\
\hline \multirow{2}{*}{ LDH $(n=43)$} & Normal & $26(60.5 \%)$ \\
\hline & High & $17(39.5 \%)$ \\
\hline
\end{tabular}

Table 2. Radiologic imaging of patients $(n=34)$

\begin{tabular}{|l|l|}
\hline \multicolumn{2}{l|}{ Chest radiography classification $(\mathbf{n = 2 1})$} \\
\hline Negative & $6(28.6 \%)$ \\
\hline Atypical & $1(4.7 \%)$ \\
\hline Indeterminate & $9(42.9 \%)$ \\
\hline Typical & $5(23.8 \%)$ \\
\hline Chest CT classification (n=20) & $3(15.0 \%)$ \\
\hline Normal & $0(0.0 \%)$ \\
\hline Non-COVID-19 & $2(10.0 \%)$ \\
\hline Indeterminate COVID-19 & $1(5.0 \%)$ \\
\hline Probable COVID-19 & $14(70.0 \%)$ \\
\hline Classic COVID-19 & \multicolumn{2}{|l}{} \\
\hline CT: Computed tomography, COVID-19: Coronavirus disease-2019
\end{tabular}


both CXR and chest CT were performed. The sensitivity of CXR and chest CT was calculated as 66.7\% [95\% confidence interval (CI) 43.0 to $85.4 \%$ ] and $83.3 \%$ (95\% CI 58.6 to $96.4 \%$ ), respectively, using RT-PCR as reference. Fourteen of the 21 COVID-19 patients (66.7\%) had parenchymal abnormalities in CXR. Twelve had bilateral and one had unilateral airspace opacities (consolidation or ground-glass opacity) while the last had prominent bronchovascular shadows only. The distribution of the airspace opacities was central and peripheral in five cases, central in four cases, and peripheral in five cases. Prominent bronchovascular shadows were observed in six cases, five of which were bilateral. The radiological findings of abnormal chest CT were given in Table 3 .

\section{Discussion}

This study defined the clinical presentation, laboratory and radiological features of symptomatic pregnant women diagnosed with SARS-CoV-2 infection either by RT-PCR testing or imaging studies.

Imaging features of COVID-19 infection in pregnant women, as in the non-pregnant population, are predominantly peripheral and bilateral patchy ground glass opacities with or without consolidation $(12,19-21)$. In this study, the radiological features were commonly seen in both central and peripheral lung tissues. This difference might be related to the phase of the disease or the diseases might progress rapidly in pregnant women (20). The other imaging features of COVID-19 were similar with previous studies $(12,20,21)$.

Three of every five pregnant women did not give consent for imaging studies involving ionizing radiation in this study. To the best of our knowledge, this finding was not previously reported. Royal College of Obstetricians and Gynecologists guidelines state that maternal health is more important than fetal health in pregnant patients (2). Therefore, radiological examination can be performed in pregnant women while exposure to ionizing radiation should be as low as reasonably achievable. In routine chest $\mathrm{CT}$, the radiation dose is approximately 4-7 $\mathrm{mGy}$, and the radiation dose of a CXR or low-dose chest $\mathrm{CT}$ is far below the accepted limit for a fetus (22). Radiation exposure of less than $100 \mathrm{mGy}$ in utero after implantation has no proven deterministic effect on the fetus. However, stochastic effects of cancer induction are known to exist, albeit slightly, and increase in proportion to dose (23). The use of radiological examinations in the diagnosis of COVID-19 pneumonia in pregnant patients requires special attention due to the risk of fetal teratogenicity caused by radiation exposure. Lung ultrasound may provide a good solution for patients who refuse chest CT or CRX $(14,24)$. The diagnostic performance of CXR in detecting COVID-19 pneumonia is lower than that of $\mathrm{CT}$, and the sensitivity was reported to be $33-69 \%$ in studies involving few non-pregnant cases (25). Chest CT sensitivity was reported to be as high as $94 \%$ in a meta-analysis (26). Similarly, the sensitivity of CXR in detecting COVID-19 pneumonia was found to be $66.7 \%$ in this study, whereas chest CT sensitivity was $86.6 \%$. The authors postulate that CXR can be used as the initial radiological examination for symptomatic pregnant patients with COVID-19 considering its relatively lower radiation dose and moderate sensitivity. However, a normal CXR cannot rule out COVID-19. In this study, ARDS development was detected in the CXR in one case and in the chest CT in two cases and, one of these cases involved concomitant pneumothorax and pneumomediastinum (Figure 3). This severe patient was treated in the ICU and required mechanical ventilation. Although spontaneous pneumomediastinum is a rare complication of COVID-19, the mechanism of pneumomediastinum is not clear (27). These individual cases have highlighted the importance of radiologic imaging, not only in diagnosing COVID-19 pneumonia, but also in detecting accompanying complications of the disease.

The most common admission symptoms of the patients included in the study were dry cough, fever, and dyspnea, which were similar with those in the non-pregnant population. Laboratory findings showed a normal leukocyte count with lymphocytopenia, and increased C-reactive protein and lactate dehydrogenase concentrations, which were similar to the findings in non-pregnant population $(28,29)$.

In our study group, six of the nine pregnant women whose first RT-PCR test was negative, had a positive result on the second RT-PCR test. Although the RT-PCR test is accepted as a reference in the diagnosis of COVID-19, the sensitivity of the test is low. The positivity rate of the first test is $60-71 \%$, and the positivity rate increases with subsequent tests (30). Thus, a diagnosis of COVID-19 should not be ruled out in pregnant patients with a single negative RT-PCR test result. Considering the method used to obtain the sample, and low sensitivity due to technical reasons, repetition of the test should not be avoided in cases where the first test is negative if clinical, laboratory, or radiological findings are consistent.

It is shown that COVID-19 in pregnancy was associated with maternal morbidity and preterm birth and required a high rate (8\%) of intensive care admission (6,9). Similarly, in this study $54.3 \%$ of all births were performed with cesarean section and the preterm birth rate was $58.8 \%$. In addition, $9.1 \%$ of the pregnant patients included in the study were admitted to the ICU, three of whom developed ARDS and one of them died. Some of the studies conducted at the beginning of the pandemic claim that the course of COVID-19 during pregnancy is not different to non-pregnant cases $(31,32)$. Contrary to these studies, our preliminary results suggest that clinical course of the COVID-19 in pregnancy seems more severe, similar to more recent studies $(7,33)$. Similar to our study results, the 
Table 3. Case-based chest CT findings of pregnant women with COVID-19

\begin{tabular}{|c|c|c|c|c|c|c|c|c|}
\hline Case & 1 & 2 & 3 & 4 & 5 & 6 & 7 & 8 \\
\hline RT-PCR & + & + & + & + & + & + & + & + \\
\hline $\begin{array}{l}\text { CT classification } \\
\text { Classic COVID-19 } \\
\text { Probable COVID-19 } \\
\text { Indeterminate COVID-19 } \\
\text { Non- COVID-19 }\end{array}$ & Classic & Classic & Classic & Classic & Classic & Classic & Classic & Classic \\
\hline $\begin{array}{l}\text { Lung involment } \\
\text { Bilateral }(\mathrm{B} / \mathrm{L}) \\
\text { Right } \\
\text { Left }\end{array}$ & $\mathrm{B} / \mathrm{L}$ & $\mathrm{B} / \mathrm{L}$ & $\mathrm{B} / \mathrm{L}$ & $\mathrm{B} / \mathrm{L}$ & $\mathrm{B} / \mathrm{L}$ & $\mathrm{B} / \mathrm{L}$ & $\mathrm{B} / \mathrm{L}$ & $\mathrm{B} / \mathrm{L}$ \\
\hline Number of lobes involved (1-5) & 5 & 5 & 5 & 5 & 4 & 5 & 5 & 5 \\
\hline Max diameter of lession (cm) & 2.1 & 5.5 & 3.5 & 6.7 & 4.7 & 3.7 & 6.6 & 2.2 \\
\hline $\begin{array}{l}\text { CT severty index } \\
\text { Mild }(\leq 5) \\
\text { Moderate }(6-11) \\
\text { Severe }(\geq 12)\end{array}$ & $\begin{array}{l}\text { Severe } \\
(18)\end{array}$ & $\begin{array}{l}\text { Moderate } \\
(7)\end{array}$ & $\begin{array}{l}\text { Severe } \\
(12)\end{array}$ & $\begin{array}{l}\text { Moderate } \\
(6)\end{array}$ & $\begin{array}{l}\text { Moderate } \\
(6)\end{array}$ & $\begin{array}{l}\text { Moderate } \\
(10)\end{array}$ & $\begin{array}{l}\text { Moderate } \\
\text { (7) }\end{array}$ & $\begin{array}{l}\text { Moderate } \\
\text { (7) }\end{array}$ \\
\hline $\begin{array}{l}\text { Distrubition of lesions } \\
\text { Peripheral (P) } \\
\text { Central (C) } \\
\text { Peripheral and central (P\&C) }\end{array}$ & $\mathrm{P} \& \mathrm{C}$ & $\mathrm{P} \& \mathrm{C}$ & $\mathrm{P} \& \mathrm{C}$ & $\mathrm{P} \& \mathrm{C}$ & $\mathrm{P} \& \mathrm{C}$ & $\mathrm{P} \& \mathrm{C}$ & $\mathrm{P} \& \mathrm{C}$ & $\mathrm{P} \& \mathrm{C}$ \\
\hline $\begin{array}{l}\text { Shape of lesions } \\
\text { Patchy } \\
\text { Diffuse }\end{array}$ & Patchy & Patchy & Patchy & Patchy & Patchy & Diffuse & Patchy & Patchy \\
\hline $\begin{array}{l}\text { Appeareance of lesions } \\
\text { Ground glass opacity (GGO) } \\
\text { Consolidation (C) } \\
\text { GGO and consolidation (GGO\&C) }\end{array}$ & GGO\&C & GGO\&C & GGO & GGO\&C & GGO\&C & GGO\&C & GGO\&C & GGO \\
\hline \multicolumn{9}{|l|}{ CT Paranchimal findings } \\
\hline Vasculer enlargement & + & - & + & - & - & + & - & - \\
\hline Intralobular reticular density & + & - & - & - & + & + & - & - \\
\hline Bronchial wall thickening & + & - & - & - & - & - & + & - \\
\hline Subpleural curvilineer lines & + & - & - & - & - & - & + & - \\
\hline Air bronchogram & - & - & - & + & - & + & - & - \\
\hline Fibrous band & + & - & - & + & + & - & - & - \\
\hline Subpleural sparing & - & + & + & - & - & + & + & - \\
\hline Halo sign & - & - & - & - & - & + & - & - \\
\hline Reversed halo sign & - & - & + & - & - & - & - & - \\
\hline \multicolumn{9}{|l|}{ Extrapulmonary manifesation } \\
\hline Pleural thickening & - & - & - & - & - & - & - & - \\
\hline Lymphadenopaty & - & - & - & - & - & - & - & - \\
\hline Pleural effusion & - & - & - & - & - & + & - & - \\
\hline $\begin{array}{l}\text { Pneumomediastenum and } \\
\text { Pneumothorax }\end{array}$ & - & - & - & - & - & - & - & - \\
\hline
\end{tabular}


Table 3. Continued

\begin{tabular}{|c|c|c|c|c|c|c|c|c|c|}
\hline Case & 9 & 10 & 11 & 12 & 13 & 14 & 15 & 16 & 17 \\
\hline RT-PCR & + & + & + & + & + & + & + & - & - \\
\hline $\begin{array}{l}\text { CT classification } \\
\text { Classic COVID-19 } \\
\text { Probable COVID-19 } \\
\text { Indeterminate COVID-19 } \\
\text { Non- COVID-19 }\end{array}$ & Classic & Classic & $\begin{array}{l}\text { Indeter- } \\
\text { minate }\end{array}$ & Classic & Classic & Classic & Classic & $\begin{array}{l}\text { Indeter- } \\
\text { minate }\end{array}$ & Probable \\
\hline $\begin{array}{l}\text { Lung involment } \\
\text { Bilateral }(\mathrm{B} / \mathrm{L}) \\
\text { Right } \\
\text { Left } \\
\end{array}$ & $\mathrm{B} / \mathrm{L}$ & Right & $\mathrm{B} / \mathrm{L}$ & $\mathrm{B} / \mathrm{L}$ & $\mathrm{B} / \mathrm{L}$ & $\mathrm{B} / \mathrm{L}$ & $\mathrm{B} / \mathrm{L}$ & $\mathrm{B} / \mathrm{L}$ & Right \\
\hline Number of lobes involved (1-5) & 5 & 2 & 2 & 4 & 5 & 3 & 5 & 2 & 2 \\
\hline Max diameter of lession $(\mathrm{cm})$ & 2.3 & 5.1 & 4.7 & 3.4 & 8 & 4.3 & 9.2 & 3.1 & 1.0 \\
\hline $\begin{array}{l}\text { CT severty index } \\
\text { Mild }(\leq 5) \\
\text { Moderate }(6-11) \\
\text { Severe }(\geq 12)\end{array}$ & Mild (5) & Mild (4) & Mild (2) & Mild (4) & $\begin{array}{l}\text { Modarete } \\
(6)\end{array}$ & Mild (3) & Severe (22) & Mild (2) & Mild (2) \\
\hline $\begin{array}{l}\text { Distrubition of lesions } \\
\text { Peripheral (P) } \\
\text { Central (C) } \\
\text { Peripheral and central (P\&C) }\end{array}$ & $\mathrm{P} \& \mathrm{C}$ & $P$ & $P$ & $\mathrm{P}$ & $\mathrm{P} \& \mathrm{C}$ & $\mathrm{P}$ & $\mathrm{P} \& \mathrm{C}$ & $\mathrm{P}$ & $\mathrm{P} \& \mathrm{C}$ \\
\hline $\begin{array}{l}\text { Shape of lesions } \\
\text { Patchy } \\
\text { Diffuse }\end{array}$ & Patchy & Patchy & Patchy & Patchy & Patchy & Patchy & Diffuse & Patchy & Patchy \\
\hline $\begin{array}{l}\text { Appeareance of lesions } \\
\text { Ground glass opacity (GGO) } \\
\text { Consolidation (C) } \\
\text { GGO and consolidation (GGO\&C) }\end{array}$ & GGO & GGO & $\mathrm{C}$ & GGO\&C & GGO & GGO & GGO\&C & GGO & GGO\&C \\
\hline \multicolumn{10}{|l|}{ CT Paranchimal findings } \\
\hline Vasculer enlargement & - & + & - & + & + & + & - & - & - \\
\hline Intralobular reticular density & - & - & - & - & + & - & + & - & - \\
\hline Bronchial wall thickening & - & - & - & - & - & - & - & - & - \\
\hline Subpleural curvilineer lines & - & - & - & - & - & - & - & - & - \\
\hline Air bronchogram & - & - & + & - & - & - & + & - & - \\
\hline Fibrous band & - & - & + & - & + & - & + & - & - \\
\hline Subpleural sparing & - & - & - & + & + & - & - & - & - \\
\hline Halo sign & - & - & - & - & - & - & - & - & - \\
\hline Reversed halo sign & - & - & - & - & - & - & - & - & - \\
\hline \multicolumn{10}{|l|}{ Extrapulmonary manifesation } \\
\hline Pleural thickening & - & + & + & + & - & - & - & - & - \\
\hline Lymphadenopaty & - & - & - & - & - & - & - & - & - \\
\hline Pleural effusion & - & - & - & - & - & - & - & - & - \\
\hline $\begin{array}{l}\text { Pneumomediastenum and } \\
\text { Pneumothorax }\end{array}$ & - & - & - & - & - & - & + & - & - \\
\hline
\end{tabular}



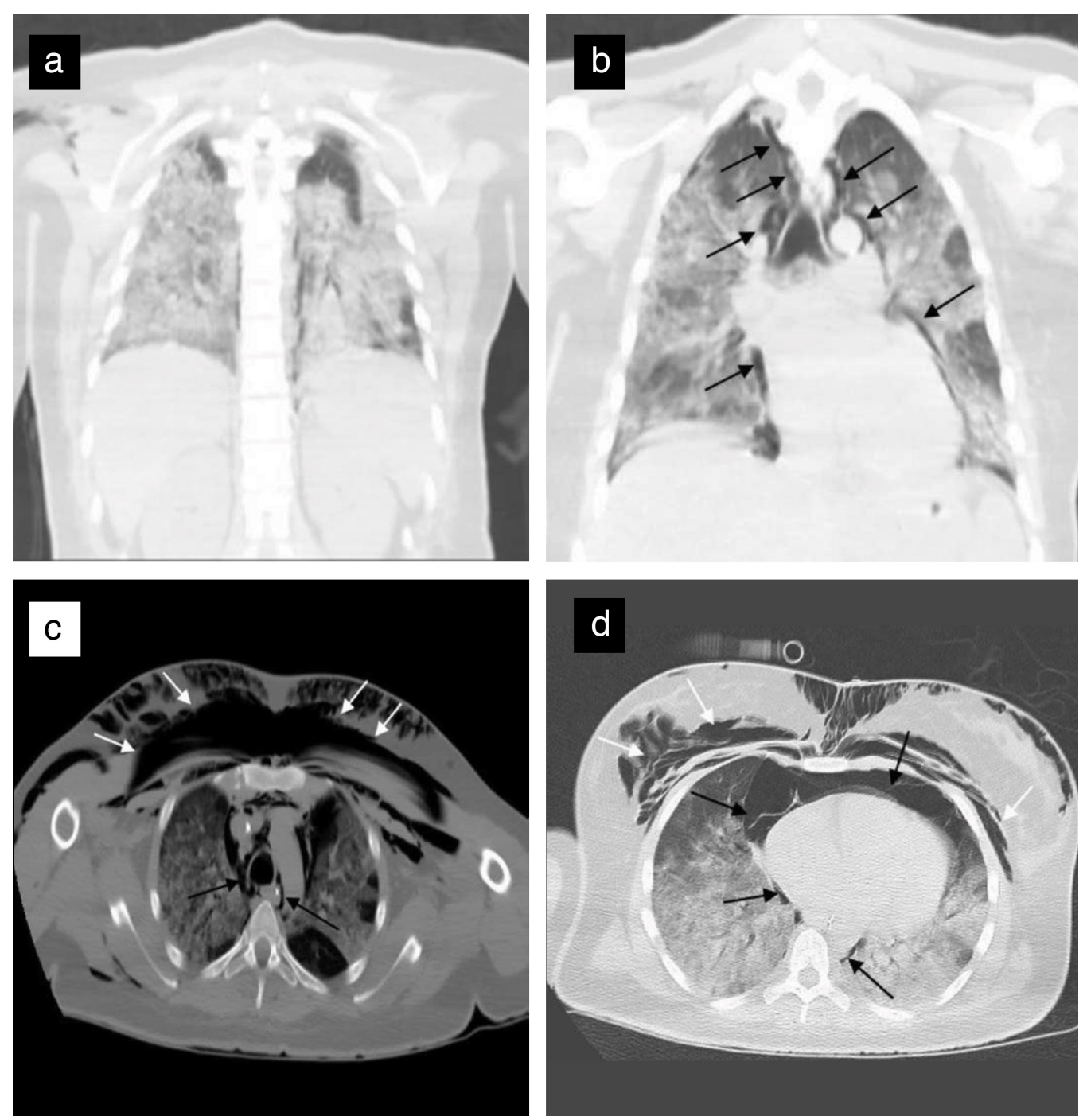

Figure 3. CT images obtained 2 hours after emergency cesarean section due to fetal distress of a 25-year-old woman with COVID-19. Coronal images $(a, b)$ show bilateral diffuse and multiple patchy ground-glass opacities with partial consolidation. CT severity index is 22 and classified as severe. All CT images (a-d) show air in the mediastinum which outlines mediastinal organs (black arrows). Also, axial CT images (c,d) show extensive subcutaneous emphysema (white arrows) in the anterior chest wall

CT: Computed tomography, COVID-19: Coronavirus disease-2019

trimester of pregnancy has been shown to affect the clinical severity of COVID-19 (34). However, in our study, although there is a percentage difference between trimesters, the reason for not having a statistically significant relationship may be the relatively small number of patients. RT-PCR test positivity was not observed in any of the delivered fetuses, which supports the notion that the disease has no vertical transmission $(35,36)$.

\section{Study limitation}

The limitations of our study are the absence of multiple RT-PCR tests in some pregnant women and the relatively low number of patients included in the study.

\section{Conclusion}

This study describes the main radiological features of symptomatic pregnant women infected with COVID-19. The refusal rate among pregnant women for the imaging modalities involving ionizing radiation was high but both $\mathrm{CXR}$ and chest CT had high sensitivity for COVID-19 diagnosis. The preterm birth and cesarean section rates were observed as remarkably increased.

Ethics Committee Approval: The study was approved by the Ethical Committee of the University of Health Sciences Turkey, Kartal Koşuyolu Training and Research Hospital (approval number: 2020.4/07-312) and the national health authorities. 


\section{Informed Consent: It was obtained.}

\section{Peer-review: Externally peer-reviewed.}

Author Contributions: Surgical and Medical Practices: T.Y.K., K.M.A., H.Ö.Ç., B.N.K., M.Y., N.T., N.Ç.Ç.; Concept: T.Y.K., M.Y.; Design: T.Y.K., K.M.A., H.Ö.Ç., B.N.K., M.Y., N.T.; Data Collection or Processing: T.Y.K., K.M.A., H.Ö.Ç., B.N.K., M.Y.; Analysis or Interpretation: T.Y.K., B.N.K., M.Y., N.Ç.Ç.; Literature Search: T.Y.K., K.M.A., H.Ö.Ç., B.N.K., M.Y.; Writing: T.Y.K., K.M.A., H.Ö.Ç., B.N.K., M.Y., N.T., N.Ç.Ç.

Conflict of Interest: No conflict of interest is declared by the authors.

Financial Disclosure: The authors declared that this study received no financial support.

\section{References}

1. Jamieson DJ, Honein MA, Rasmussen SA, Williams JL, Swerdlow DL, Biggerstaff MS, et al; Novel Influenza A (H1N1) Pregnancy Working Group. H1N1 2009 influenza virus infection during pregnancy in the USA. Lancet 2009; 374: 451-8. https://doi.org/10.1016/S01406736(09)61304-0.

2. Coronavirus (COVID-19) infection and pregnancy. (Accessed May 18, 2020). The Royal College of Obstetricians and Gynaecologists guidance n.d. https:/www.rcog.org.uk/ coronavirus-pregnancy

3. Wong SF, Chow KM, Leung TN, Ng WF, Ng TK, Shek CC, et al. Pregnancy and perinatal outcomes of women with severe acute respiratory syndrome. Am J Obstet Gynecol 2004; 191: 292-7.

4. Schwartz DA, Graham AL. Potential Maternal and Infant Outcomes from (Wuhan) Coronavirus 2019-nCoV Infecting Pregnant Women: Lessons from SARS, MERS, and Other Human Coronavirus Infections. Viruses 2020; 12: 194.

5. Alfaraj SH, Al-Tawfiq JA, Memish ZA. Middle East Respiratory Syndrome Coronavirus (MERS-CoV) infection during pregnancy: Report of two cases \& review of the literature. J Microbiol Immuno Infect 2019; 52: 501-3.

6. Savasi VM, Parisi F, Patanè L, Ferrazzi E, Frigerio L, Pellegrino A, et al. Clinical Findings and Disease Severity in Hospitalized Pregnant Women With Coronavirus Disease 2019 (COVID-19). Obstet Gynecol 2020; 136: 252-8.

7. Zaigham M, Andersson O. Maternal and perinatal outcomes with COVID-19: A systematic review of 108 pregnancies. Acta Obstet Gynecol Scand 2020; 99: 823-9.

8. Centers for Disease Control and Prevention. (accessed July 30, 2020). If You Are Pregnant, Breastfeeding, or Caring for Young Children. CDC 2020: 1. https://www.cdc.gov/coronavirus/2019ncov/need-extra-precautions/pregnancy-breastfeeding.html

9. Sentilhes L, De Marcillac F, Jouffrieau C, Kuhn P, Thuet V, Hansmann Y, et al. Coronavirus disease 2019 in pregnancy was associated with maternal morbidity and preterm birth. Am J Obstet Gynecol 2020; 223: 914.e1-15.

10. Yassa M, Mutlu MA, Birol P, Kuzan TY, Kalafat E, Usta C, et al. Lung ultrasonography in pregnant women during the COVID-19 pandemic: an interobserver agreement study among obstetricians. Ultrasonography 2020; 39: 340-9.
11. Huang P, Liu T, Huang L, Liu H, Lei M, Xu W, et al. Use of Chest CT in Combination with Negative RT-PCR Assay for the 2019 Novel Coronavirus but High Clinical Suspicion. Radiology 2020; 295: 22-3.

12. Kuzan TY, Murzoglu Altıntoprak K, Ciftci HO, Ergul U, Unal Ozdemir $\mathrm{NB}$, Bulut M, et al. A comparison of clinical, laboratory and chest CT findings of laboratory-confirmed and clinically diagnosed COVID-19 patients at first admission. Diagn Interv Radiol 2021; 27: 336-43.

13. Ai T, Yang Z, Hou H, Zhan C, Chen C, Lv W, et al. Correlation of Chest CT and RT-PCR Testing for Coronavirus Disease 2019 (COVID-19) in China: A Report of 1014 Cases. Radiology 2020; 296: E32-40.

14. Yassa M, Yirmibes C, Cavusoglu G, Eksi H, Dogu C, Usta C, et al. Outcomes of universal SARS-CoV-2 testing program in pregnant women admitted to hospital and the adjuvant role of lung ultrasound in screening: a prospective cohort study. J Matern Fetal Neonatal Med 2020; 33: 3820-6.

15. COVID-19 (SARS-CoV-2 INFECTION) GUIDE-Study of Scientific Board Turkish Ministry of Health, Ankara, Turkey. (accessed September 12, 2020) n.d. https://covid19.saglik.gov.tr/

16. Foust AM, Phillips GS, Chu WC, Daltro P, Das KM, Garcia-Peña P, et al. International Expert Consensus Statement on Chest Imaging in Pediatric COVID-19 Patient Management: Imaging Findings, Imaging Study Reporting, and Imaging Study Recommendations. Radiol Cardiothorac Imaging 2020; 2: e200214.

17. British Society of Thoracic Imaging. Thoracic Imaging in COVID 19 Infection Guidance for the Reporting Radiologist Version 2 n.d. https://www.bsti.org.uk/standards-clinical-guidelines/clinicalguidelines/bsti-covid-19-guidance-for-the-reporting-radiologist/

18. Xie X, Zhong Z, Zhao W, Zheng C, Wang F, Liu J. Chest CT for Typical Coronavirus Disease 2019 (COVID-19) Pneumonia: Relationship to Negative RT-PCR Testing. Radiology 2020; 296: E41-5.

19. Bernheim A, Mei X, Huang M, Yang Y, Fayad ZA, Zhang N, et al. Chest CT Findings in Coronavirus Disease-19 (COVID-19): Relationship to Duration of Infection. Radiology 2020; 295: 200463.

20. Wu X, Sun R, Chen J, Xie Y, Zhang S, Wang X. Radiological findings and clinical characteristics of pregnant women with COVID-19 pneumonia. Int J Gynecol Obstet 2020; 150: 58-63.

21. Han R, Huang L, Jiang H, Dong J, Peng H, Zhang D. Early Clinical and CT Manifestations of Coronavirus Disease 2019 (COVID-19) Pneumonia. Am J Roentgenol 2020; 215: 338-43.

22. Guidelines for Diagnostic Imaging During Pregnancy and Lactation | ACOG. (accessed May 18, 2020). n.d. https://www.acog.org/ clinical/clinical-guidance/committee-opinion/articles/2017/10/ guidelines-for-diagnostic-imaging-during-pregnancy-and-lactation

23. Rajaraman P, Simpson J, Neta G, Berrington de Gonzalez A, Ansell $\mathrm{P}$, Linet MS, et al. Early life exposure to diagnostic radiation and ultrasound scans and risk of childhood cancer: case-control study. BMJ 2011; 342: d472.

24. Yassa M, Birol P, Mutlu AM, Tekin AB, Sandal K, Tug N. Lung Ultrasound Can Influence the Clinical Treatment of Pregnant Women With COVID-19. J Ultrasound Med 2021; 191-203. https:// doi.org/10.1002/jum.15367

25. Güneyli S, Atçeken Z, Doğan H, Altınmakas E, Atasoy KÇ. Radiological approach to COVID-19 pneumonia with an emphasis on chest CT. Diagn Interv Radiol 2020; 26: 323-32.

26. Kim H, Hong H, Yoon SH. Diagnostic Performance of CT and Reverse Transcriptase Polymerase Chain Reaction for Coronavirus Disease 2019: A Meta-Analysis. Radiology 2020; 296: E145-55. https://doi. org/10.1148/radiol.2020201343

27. Gorospe L, Ayala-Carbonero A, Ureña-Vacas A, Fra Fernández S, Muñoz-Molina GM, Arrieta P, et al. Spontaneous Pneumomediastinum in Patients With COVID-19: A Case Series of Four Patients. Arch Bronconeumol 2020; 56: 754-6. 
28. Liu H, Liu F, Li J, Zhang T, Wang D, Lan W. Clinical and CT imaging features of the COVID-19 pneumonia: Focus on pregnant women and children. J Infect 2020; 80: e7-13.

29. Shi H, Han X, Jiang N, Cao Y, Alwalid O, Gu J, et al. Radiological findings from 81 patients with COVID-19 pneumonia in Wuhan, China: a descriptive study. Lancet Infect Dis 2020; 20: 425-34.

30. Caruso D, Zerunian M, Polici M, Pucciarelli F, Polidori T, Rucci C, et al. Chest CT Features of COVID-19 in Rome, Italy. Radiology 2020; 296: E79-85.

31. Liu D, Li L, Wu X, Zheng D, Wang J, Yang L, et al. Pregnancy and Perinatal Outcomes of Women With Coronavirus Disease (COVID-19) Pneumonia: A Preliminary Analysis. Am J Roentgenol 2020; 215: 127-32.

32. Yu N, Li W, Kang Q, Xiong Z, Wang S, Lin X, et al. Clinical features and obstetric and neonatal outcomes of pregnant patients with COVID-19 in Wuhan, China: a retrospective, single-centre, descriptive study. Lancet Infect Dis 2020; 20: 559-64.
33. Pierce-Williams RAM, Burd J, Felder L, Khoury R, Bernstein PS, Avila K, et al. Clinical course of severe and critical coronavirus disease 2019 in hospitalized pregnancies: a United States cohort study. Am J Obstet Gynecol MFM 2020; 2: 100134.

34. Tug N, Yassa M, Köle E, Sakin Ö, Çakır Köle M, Karateke A, et al. Pregnancy worsens the morbidity of COVID-19 and this effect becomes more prominent as pregnancy advances. Turk J Obstet Gynecol 2020; 17: 149-54.

35. Chen H, Guo J, Wang C, Luo F, Yu X, Zhang W, et al. Clinical characteristics and intrauterine vertical transmission potential of COVID-19 infection in nine pregnant women: a retrospective review of medical records. Lancet 2020; 395: 809-15.

36. Zhu H, Wang L, Fang C, Peng S, Zhang L, Chang G, et al. Clinical analysis of 10 neonates born to mothers with 2019-nCoV pneumonia. Transl Pediatr 2020; 9: 51-60. 